\title{
Urban-rural difference in patients utilizing the service of telehealthcare
}

\author{
Lichin Chen ${ }^{* 1,2}$, Te-Wei Ho ${ }^{3}$, Chih-Yuan Shih ${ }^{4}$, Fong-Ci Lin ${ }^{3}$, Feipei Lai ${ }^{3,5,6}$, Jing-Wen Guo ${ }^{7}$, Mei-Hua Zhuang ${ }^{7}$ \\ ${ }^{1}$ Center for Systems and Synthetic Biology, National Yang Ming University, Taipei, Taiwan \\ ${ }^{2}$ School of Nursing, National Yang Ming University, Taipei, Taiwan \\ ${ }^{3}$ Graduate Institute of Biomedical Electronics and Bioinformatics, National Taiwan University, Taipei, Taiwan \\ ${ }^{4}$ Department of Family Medicine, National Taiwan University Hospital Jin-Shan Branch, New Taipei City, Taiwan \\ ${ }^{5}$ Department of Computer Science and Information Engineering, National Taiwan University, Taipei, Taiwan \\ ${ }^{6}$ Department of Electrical Engineering, National Taiwan University, Taipei, Taiwan \\ ${ }^{7}$ Department of Nursing, National Taiwan University Hospital Jin-Shan Branch, New Taipei City, Taiwan
}

Received: July 2, 2015

DOI: $10.5430 /$ jha.v4n6p56
Accepted: August 27, $2015 \quad$ Online Published: September 2, 2015

URL: http://dx.doi.org/10.5430/jha.v4n6p56

\begin{abstract}
There are concerns about the unbalanced distribution of healthcare resources between rural and urban areas. There have been attempts to use existing healthcare resources more effectively through telehealthcare. Usability is an important indicator for evaluating patient behavior and determining service improvements. Nevertheless, usability has not been studied extensively enough. This study analyzed the usability differences between urban and rural areas in Taiwan for a web portal used in a telehealthcare program. Data were collected for two years. Usability data includes the frequency of web portal patient logins, the frequency of glucose measurements, whether the records were transmitted to the system through $3 \mathrm{G}$ networks automatically or were manually inputted, and the correlation of the mean 3-month daily glucose levels and $\mathrm{HbA}_{1} \mathrm{c}$ results. Patients in urban areas logged into the web portal more frequently $(p<.001)$ and recorded glucose levels more frequently $(p=.003)$. More patients in the rural area transmitted their daily glucose levels using devices $(p<.001)$. Mean 3-month daily glucose levels and $\mathrm{HbA}_{1} \mathrm{c}$ results appear to be highly consistent. Patients in urban areas did not readily change glucometer habits but were willing to log in to web portal and record daily glucose levels manually. Patients in rural areas were willing to use the $3 \mathrm{G}$ glucometer to transmit data more frequently. For patients in urban areas, web portals should provide more information and smart applications. For patients in rural areas, the application should be simple and easy to use.
\end{abstract}

Key Words: Telehealthcare, Telemedicine, Usability, Web portal, Urban-rural difference

\section{INTRODUCTION}

There are concerns about the unbalanced distribution of healthcare resources between rural and urban areas for patients with diabetes mellitus. ${ }^{[1,2]}$ In rural areas, patients are at higher risk than those in urban areas due to lessfrequent visits to the physician as well as less access to specialized care. ${ }^{[3-5]}$ Longer travel distance to the hospital is related to lower odds of receiving guideline-concordant care. ${ }^{[6]}$ Compared with urban patients, rural patients tend to have fewer visits, enter care later in the disease progression, have more serious symptoms at entry, receive lower-quality care, and need more expensive treatment. ${ }^{[6]}$ Some special-

*Correspondence: Lichin Chen; Email: i.shiou@ym.edu.tw; Address: Center for Systems and Synthetic Biology, National Yang Ming University, No.155, Sec.2, Linong Street, Taipei, 112, Taiwan. 
ists have attempted to solve this problem using technologysupported telehealthcare, ${ }^{[2]}$ which supports patient monitoring and long-distance patient-physician communication. ${ }^{\text {[-11] }}$ Telehealthcare, which has been proven effective in diabetes control, ${ }^{[12,13]}$ facilitates disease management and longitudinal health status monitoring and aims to use existing healthcare resources more effectively and reduce hospitalizations without increasing mortality. ${ }^{[14-19]}$

Some studies applied telemedicine technology in dermatology and depression management in urban and rural areas. They found out that the clinical outcomes of the telemedicine are similar to the conventional care, ${ }^{[5]}$ meanwhile with less travel and time cost for the patients. ${ }^{[5,20]}$ However, the additional costs of equipments does make telemedicine technology expensive. ${ }^{[5,6]}$ A number of diabetes telehealthcare programs include patient self-management information systems, commonly known as patient portals or web portals. ${ }^{[21,22]}$ These facilitate self-care for diabetic patients while they are away from medical institutes. Between urban and rural areas, researchers have observed that for most patients, Internet access itself is not a primary barrier to the use of electronic health applications, ${ }^{[22]}$ and that the attitudes of patients to receiving medical care through a telehealthcare service were both positive and receptive. ${ }^{[2]}$ However, patients in different regions may have different requirements. Observing the way patients utilize telehealthcare services is essential for service adjustments, and usability is an important indicator representing interaction between patients and web portals or electronic health applications. ${ }^{[21]}$ Nevertheless, usability has been studied less extensively, mostly focusing on questionnaires or interviews rather than performance testing, ${ }^{21,23,24]}$ and few studies have evaluated the usability differences between urban and rural areas. The aim of this study is to further investigate the way patients utilize telehealthcare services and compare usability differences between patients in urban and rural areas. The Methods section first briefly describes the hospital at which this study took place, the telehealthcare program mentioned in this research, patient enrollment, data collection, and the way the data is analyzed. The Results section presents the findings, which are further interpreted in the Discussion section. Finally, this research is concluded with the Conclusion section.

\section{METHOD}

This study was conducted in a teaching hospital in Taiwan, which in 2011 initiated a telehealthcare program for diabetes patients to provide a long-distance healthcare service. The program included a teleconsultant service, a web portal that is integrated with a third-generation mobile telecommunication $(3 \mathrm{G})$ glucometer. ${ }^{[7,25]}$ The teaching hospital had 5

Published by Sciedu Press branches, one of which was the Taipei city branch, where the telehealthcare program was launched. In 2012, after additional development on the program, the service was extended to the Jin-Shan branch. Taipei City is the capital of Taiwan, and the Jin-Shan region is a small region in the countryside that contains a mere $0.8 \%$ of the population $(n=22,400)$ of Taipei City $(n=2,702,315) .{ }^{[26,27]}$ The program in the two branches provided the same service. In this research, the Taipei City branch was classified as being in an urban area and the Jin-Shan branch as being in a rural area. After operations in the second branch stabilized, it became interested in how patients accept the technology, and thus inspired this study to further observe the usability of the service and to compare the urban and rural areas in terms of how patients utilized the telehealthcare service.

Data were collected for two years (from January 2012 to December 2013). Patients diagnosed with either Type 1 or Type 2 diabetes mellitus and with an $\mathrm{HbA}_{1} \mathrm{c}$ level greater than 7.5 , or those identified as not well-controlled, were recruited under informed consent. Those with severe diabetes complications that could affect the participation of the study were excluded from the analysis. Also excluded from this study were those who provided fewer than 15 glucose measurements during the data collection period, which represent submitting measurements less than 2 times each month. Usability analysis includes the frequency of patients who logged into the web portal, the frequency of their glucose measurements, and whether the records were transmitted to the system through $3 \mathrm{G}$ networks automatically or were manually inputted. The frequency differences between the two groups of patients logging in to submit glucose measurements were compared with an independent $T$-test. The differences between patients who used $3 \mathrm{G}$ data transmission from those who used manual input were compared with chisquare tests. Also, in this study we grouped the daily glucose measurements uploaded by patients in 3-month intervals and validated the consistency of the mean 3-month daily glucose levels and the $\mathrm{HbA}_{1} \mathrm{c}$ results. This study compared the overall consistency (urban and rural patients together) and the consistency of urban and rural patients respectively. Validation was performed with person correlation tests. Finally, the differences of glucose levels and $\mathrm{HbA}_{1} \mathrm{c}$ control of the patients in both areas for each year were compared, also using an independent $T$-test. Data was analyzed using SPSS for Windows version 20 (SPSS Inc, Chicago, IL, USA).

\section{Results}

One hundred and seventy-six patients entered the program, of whom 56 were excluded due to missing information, failure to not transmit data, or transmissions of fewer than 15 glu- 
cose measurements during the data collection period. One hundred and twenty patients remained and were included the analysis. Eighty-seven participants $(72.50 \%)$ were from Taipei City (urban area) and 33 were (27.5\%) from the JinShan region (rural area). Table 1, which contains the demographic information of the enrolled participants, validates the differences among the demographic variables between the two groups. In particular, it can be observed that patients in the urban area had significantly higher frequencies of web portal logins $(p<.001)$ and significantly higher frequencies of glucose record submissions $(p=.003)$.

Table 1. Demographic information of enrolled patients

\begin{tabular}{|c|c|c|c|c|}
\hline & & Urban & Rural & $p$-value \\
\hline \multirow{2}{*}{ Gender } & Male (\%) & $45(75.0)$ & $15(25.0)$ & \\
\hline & Female (\%) & $36(66.7)$ & $18(33.3)$ & \\
\hline Age & Mean $\pm S D$ & $53.21 \pm 13.45$ & $56.42 \pm 13.20$ & .247 \\
\hline BMI & Mean $\pm S D$ & $25.31 \pm 3.76$ & $25.40 \pm 5.54$ & .929 \\
\hline $\begin{array}{l}\text { Access } \\
\text { times }\end{array}$ & Mean $\pm S D$ & $99.37 \pm 179.74$ & $14.97 \pm 56.22$ & $.000^{* *}$ \\
\hline $\begin{array}{l}\text { Glucose } \\
\text { records }\end{array}$ & Mean $\pm S D$ & $528.63 \pm 639.09$ & $266.33 \pm 283.42$ & $.003^{*}$ \\
\hline
\end{tabular}

Table 2 is a comparison of how patients recorded their daily glucose levels. It appears that more rural patients transmitted their daily glucose levels using devices than those in urban areas $(p<.001)$. Table 3 shows the consistency between the mean 3-month daily glucose level and the $\mathrm{HbA}_{1} \mathrm{c}$ results. It appears that the two values are highly consistent $(p<.001)$, even when the two areas are observed separately $(p<.001$, $p=.011)$. Table 4 shows that both areas showed improved glucose control and decreased glucose variances. However, there was no further evidence of any differences in glucose or $\mathrm{HbA}_{1} \mathrm{c}$ control between the two groups.

Table 2. Comparison of location and daily glucose submission methods

\begin{tabular}{llllll}
\hline & $\begin{array}{l}\text { Manual input } \\
\text { (\%) }\end{array}$ & $\begin{array}{l}\text { Auto transmit } \\
\text { by device (\%) }\end{array}$ & Total & $\begin{array}{l}\text { Upload } \\
\text { frequency } \\
\text { (monthly) }\end{array}$ & p-value \\
\hline Urban & $15,862(37.04)$ & $26,957(62.96)$ & 42,819 & 14.87 & $.000^{* *}$ \\
Rural & $1,529(17.40)$ & $7,260(82.60)$ & 8,789 & 11.10 & \\
Total & 17,391 & 34,217 & 51,608 & 17.92 & \\
${ }^{* *} p<.001$ & & & & &
\end{tabular}

\section{Discussion}

The intention when implementing new technologies is to improve patient outcomes. Unlike therapeutic devices that directly affect patients, information technology's effect in is changing the way the patient's condition is understood and the way in which care is delivered. ${ }^{[28]}$ Usability, which concerns the way patients utilize the telehealthcare service, is an important indicator for determining future service adjustments and can also yield opportunities to gain further insight into patient status. ${ }^{[29]}$

Table 3. Consistency validation of mean glucose and $\mathrm{HbA}_{1} \mathrm{c}$ results

\begin{tabular}{llllll}
\hline \multirow{2}{*}{ Overall } & & Mean & SD & $\boldsymbol{R}$-value & $\boldsymbol{p}$-value \\
\hline \multirow{2}{*}{ Urban } & $\mathrm{HbA}_{1} \mathrm{C}$ & 8.85 & 19.93 & 0.414 & $.000^{* *}$ \\
& Mean glucose & 147.87 & 64.35 & & \\
& $\mathrm{HbA}_{1} \mathrm{C}$ & 8.93 & 21.05 & 0.400 & $.000^{* *}$ \\
& Mean glucose & 146.86 & 63.92 & & \\
\multirow{2}{*}{ Rural } & $\mathrm{HbA}_{1} \mathrm{C}$ & 8.13 & 2.21 & 0.545 & $.011^{*}$ \\
& Mean glucose & 152.83 & 66.16 & & \\
\hline
\end{tabular}

Note. SD: Standard deviation; ${ }^{*} p<.01 ;{ }^{* *} p<.001$

Table 4. Comparison between two areas in terms of glucose control

\begin{tabular}{lllll}
\hline & & Mean & SD & p-value \\
\hline \multirow{2}{*}{ Glucose (year 1) } & Urban & 147.90 & 26.85 & .055 \\
& Rural & 180.69 & 60.03 & \\
$\mathrm{HbA}_{1} \mathrm{c}$ (year 1) & Urban & 9.02 & 11.09 & .861 \\
& Rural & 8.54 & 1.96 & \\
\multirow{2}{*}{ Glucose (year 2) } & Urban & 145.35 & 20.72 & .275 \\
& Rural & 158.61 & 39.02 & \\
$\mathrm{HbA}_{1} \mathrm{c}$ (year 2) & Urban & 7.50 & 0.79 & .317 \\
& Rural & 7.93 & 0.69 & \\
\hline
\end{tabular}

Note. SD: Standard deviation

The results show no significant differences for patients from the two areas in gender, age, and BMI; this is indicative of similar populations for the two groups. Urban patients tended to use the web portal more often than rural patients; this indicates that they were more familiar with information technology and more willing to use it to support their daily self-care. However, while still keeping more daily glucose measurements, patients in the urban area used $3 \mathrm{G}$ data transmission less frequently than patients in the rural area. This may be because some urban patients already had a glucometer and were unwilling to make changes as they participated in the program, and thus tended to login and record their glucose levels manually. This may have affected the frequency of web portal logins for urban patients as well. At the same time, rural patients may not have viewed daily glucose measurements as a routine practice, and were willing to use the new device provided to them.

The telehealthcare assessment relied heavily on data that represents patient conditions; further caution is needed with respect to the reliability of patient-reported data. ${ }^{[30]}$ The consistency between the mean 3-month daily glucose level and the $\mathrm{HbA}_{1} \mathrm{c}$ results shows highly consistency in this research, indicating that the daily data reliably represents patient con- 
ditions. Although both groups showed a decrease in $\mathrm{HbA}_{1} \mathrm{c}$ levels in the second year of their participation, no further evidence indicated that the two regions benefitted in other ways from the telehealthcare service. Usability was also affected by the degree to which patients were familiar with technology; however, this research did not further investigate the patients' level of familiarity with technology or whether they had access to the Internet regularly. This is thus a limitation of this study.

Usability of the web portal represents the way patients utilize the telehealthcare service. Thus when trying to more evenly distribute healthcare resources, one important indicator to understanding whether regional service adjustments or different requirements are needed is to evaluate the usability differences of patients between urban and rural areas. Usability analysis offers an opportunity to gain further insight into patient daily self-care activities and to find out how patients interact with the service.

In this study, the result shows that patients in urban areas may already be used to self-monitoring blood glucose levels, and were not likely to change their glucose monitoring prac- tices when participating in the telehealthcare service, even when it could reduce their efforts in recording measurements. However, they remained highly involved and were willing to record their daily glucose levels by logging into the web portal and inputting the values manually. At the same time, patients in rural areas also showed highly participated, and were willing to use the new technologies to assist them in improving their control over diabetes. Based on the results, it appears that while patients in urban areas are willing to login to web portals, these portals should include more information and smart applications. For patients in rural areas, the application ought to be simple and easy to use. The results also show that patient-reported data is reliable and highly consistent with blood test results. Telehealthcare is beneficial for patients with chronic diseases. In the way patients use telehealthcare services, differences exist between urban and rural areas; more research is needed to address these differences and provide healthcare that better meets patient needs.

\section{CONFLicts OF InTEREST Disclosure}

No competing financial interests exist.

\section{REFERENCES}

[1] Shaw JE, Sicree RA, Zimmet PZ. Global estimates of the prevalence of diabetes for 2010 and 2030. Diabetes Research and Clinical Practice. 2010; 87(1): 4-14. PMid: 19896746. http://dx.doi.org/1 $0.1016 /$ j.diabres.2009.10.007

[2] Grubaugh AL, Cain GD, Elhai JD, et al. Attitudes toward medical and mental health care delivered via telehealth applications among rural and urban primary care patients. The Journal of Nervous and Mental Disease. 2008; 196(2): 166-170. PMid: 18277227. http://dx.doi.org/10.1097/NMD.0b013e318162aa2d

[3] Brown M, Kuhlman D, Larson L, et al. Does availability of expanded point-of-care services improve outcomes for rural diabetic patients? Primary Care Diabetes. 2013; 7(2): 129-134. PMid: 23523626. http://dx.doi.org/10.1016/j.pcd.2013.01.008

[4] McIlhenny C, Guzic B, Knee D, et al. Using technology to deliver healthcare education to rural patients. Rural Remote Health. 2011; 11(4): 1798. PMid: 21995854.

[5] Loane M, Bloomer S, Corbett R, et al. A randomized controlled trial assessing the health economics of realtime teledermatology compared with conventional care: an urban versus rural perspective. Journal of Telemedicine and Telecare. 2001; 7(2): 108-118. PMid: 11331049. http://dx.doi.org/10.1258/1357633011936246

[6] Pyne JM, Fortney JC, Tripathi SP, et al. Cost-effectiveness analysis of a rural telemedicine collaborative care intervention for depression. Archives of General Psychiatry. 2010; 67(8): 812-821. PMid: 20679589. http://dx.doi.org/10.1001/archgenpsyc hiatry. 2010.82

[7] Chen LC, Chen CW, Weng YC, et al. An information technology framework for strengthening telehealthcare service delivery.
Telemedicine and e-Health. 2012; 18(8): 596-603. http://dx.doi .org/10.1089/tmj.2011.0267

[8] Watson AJ, Kvedar JC, Rahman B, et al. Diabetes connected health: a pilot study of a patient-and provider-shared glucose monitoring web application. Journal of Diabetes Science and Technology. 2009; 3(2): 345-352. PMid: 20144366. http://dx.doi.org/10.1177 /193229680900300216

[9] Lim S, Kang SM, Shin H, et al. Improved glycemic control without hypoglycemia in elderly diabetic patients using the ubiquitous healthcare service, a new medical information system. Diabetes Care. 2011; 34(2): 308-313. PMid: 21270188. http://dx.doi .org/10 . $2337 / d c 10-1447$

[10] Klonoff DC. Using telemedicine to improve outcomes in diabetes-An emerging technology. Journal of Diabetes Science and Technology. 2009; 3(4): 624-627. PMid: 20144303. http://dx.doi.org/10. $1177 / 193229680900300401$

[11] Hess R, Bryce CL, Paone S, et al. Exploring challenges and potentials of personal health records in diabetes self-management: implementation and initial assessment. Telemedicine and e-Health. 2007; 13(5): 509-518. PMid: 17999613. http://dx.doi.org/10.1089/tmj .2006 .0089

[12] Chiu H-Y, Chen C-M. Telenursing: The Integration of Information Technology and Community Health Nursing. Yuan-Yuan Nursing. 2010; 4(2): 5-10.

[13] Heinemann L. Measuring Glucose Concentrations: Daily Practice, Current and Future Developments. Journal of Diabetes Science and Technology (Online). 2008; 2(4): 710. http://dx.doi.org/10. $1177 / 193229680800200425$

[14] Huang EW, Hung RS, Chiou SF, et al. Design and Development of a Tele-Healthcare Information System Based on Web Services 
and HL7 Standards. Software Tools and Algorithms for Biological Systems. 2011; 599-606. http://dx.doi.org/10.1007/978-1 -4419-7046-6_61

[15] Dorr D, Bonner LM, Cohen AN, et al. Informatics systems to promote improved care for chronic illness: a literature review. Journal of the American Medical Informatics Association. 2007; 14(2): 156-163. PMid: 17213491. http://dx.doi.org/10.1197/jamia.M2255

[16] McLean S, Protti D, Sheikh A. Telehealthcare for long term conditions. BMJ. 2011; 342: 374-378. PMid: 21292710. http://dx.d oi.org/10.1136/bmj.d120

[17] Dhillion JS, Lutteroth C, Wunsche BC. Leveraging Web 2.0 and Consumer Devices for Improving Elderlies Health. Paper presented at the Proceedings of the Fifth Australasian Workshop on Health Informatics and Knowledge Managemen (HIKM 2011), Perth, Australia. 2011.

[18] Mohktar MS, Basilakis J, Redmond SJ, et al. A guideline-based decision support system for generating referral recommendations from routinely recorded home telehealth measurement data. $\mathrm{Pa}$ per presented at the 32nd Annual International Conference of the IEEE EMBS, Argentina. 2010, Auguest 31 - September 4. http: //dx.doi.org/10.1109/iembs. 2010.5627766

[19] Jennett P, Andruchuk K. Telehealth:'real life' implementation issues. Computer Methods and Programs in Biomedicine. 2001; 64(3): 169174. http://dx.doi.org/10.1016/S0169-2607(00)00136-X

[20] Call VR, Erickson LD, Dailey NK, et al. Attitudes Toward Telemedicine in Urban, Rural, and Highly Rural Communities. Telemedicine and e-Health. 2015. PMid: 25839334. http://dx .doi.org/10.1089/tmj.2014.0125

[21] Britto MT, Jimison HB, Munafo JK, et al. Usability testing finds problems for novice users of pediatric portals. Journal of the American Medical Informatics Association. 2009; 16(5): 660-669. PMid: 19567793. http://dx.doi.org/10.1197/jamia.M3154

[22] Ronda MC, Dijkhorst-Oei L-T, Rutten GE. Reasons and Barriers for Using a Patient Portal: Survey Among Patients With Diabetes Mellitus. Journal of Medical Internet Research. 2014; 16(11): e263. PMid: 25424228. http://dx.doi.org/10.2196/jmir. 3457
[23] Byczkowski TL, Munafo JK, Britto MT. Family perceptions of the usability and value of chronic disease web-based patient portals. Health Informatics Journal. 2014; 20(2): 151-162. PMid: 24056751. http://dx.doi.org/10.1177/1460458213489054

[24] Jones JB, Weiner JP, Shah NR, et al. The Wired Patient: Patterns of Electronic Patient Portal Use Among Patients With Cardiac Disease or Diabetes. Journal of Medical Internet Research. 2015; 17(2): e42. PMid: 25707036. http://dx.doi.org/10.2196/jmir. 3157

[25] Chen L, Chuang L-M, Chang C-H, et al. Evaluating self-management behaviors of diabetic patients in a telehealthcare program: longitudinal study over 18 months. Journal of Medical Internet Research. 2013; 15(12): e266. PMid: 24323283. http://dx.doi.org/10. 2196/jmir. 2699

[26] New Taipei City Government. Population Information. 2014. Available from: http://www.ntpc.gov.tw/ch/home.jsp?id $=1811 \&$ websitelink=artwebsite $\cdot$ jsp\&parentpath $=0,5,56$ 9,570

[27] Taipei City Government. Population Informaiton. 2014. Available from: http: //www.gov.taipei/mp.asp?mp=100001

[28] Jeskey M, Card E, Nelson D, et al. Nurse adoption of continuous patient monitoring on acute post-surgical units: managing technology implementation. Journal of Nursing Management. 2011; 19: 863-875. PMid: 21988434. http://dx.doi.org/10.1111/j.1365-2834. 2011.01295.x

[29] Weissman JS, Schneider EC, Weingart SN, et al. Comparing patientreported hospital adverse events with medical record review: do patients know something that hospitals do not? Annals of Internal Medicine. 2008; 149(2): 100-108. PMid: 18626049. http://dx.d oi.org/10.7326/0003-4819-149-2-200807150-00006

[30] Tisnado DM, Adams JL, Liu H, et al. What is the concordance between the medical record and patient self-report as data sources for ambulatory care? Medical Care. 2006; 44(2): 132-140. PMid: 16434912.http://dx.doi.org/10.1097/01.mlr.0000 $196952.15921 . \mathrm{bf}$ 